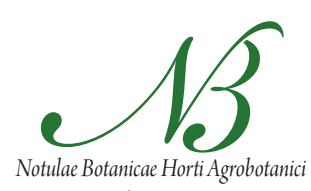

Cluj-Napoca

\title{
The Effect of Climate Change and Air Pollution on Allergenic Potential of Pollens
}

\author{
Doina A. TODEA ${ }^{1}$, Iuliu SUATEAN²*, Andreea C. COMAN', Loredana E. ROSCA' ${ }^{1}$ \\ 1 "Iuliu Hatieganu" University of Medicine and Pharmacy, Faculty of Medicine, Pneumology Department, Cluj- \\ Napoca,Romania;doina_adina@yahoo.com,dede_coman@yahoo.com,loredanarosca@yahoo.com \\ ${ }^{2}$ University of Agricultural Sciences and Veterinary Medicine Cluj-Napoca, 3-5 Manastur, 400372 \\ Cluj-Napoca, Romania; isuateani@yahoo.com (*correspondingauthor)
}

\begin{abstract}
Climate change is associated with atmospheric warming due to continuous increase in anthropogenic greenhouse gas concentration following the industrial revolution. The urban areas are more responsible for these changes. Europe for example has experienced a progressive warming $+0.9{ }^{\circ} \mathrm{C}$ for $1901-2005$. Climate change is unequivocal and represents a possible threat for patients affected by allergic conditions because it is related with an increased distribution and concentration of pollen. Higher temperature, wet condition (especially thunderstorms), wind speed, transition of cold fronts, environmental changes (allergenic pollens arrived in new areas), are mechanisms which involve changes of production, dispersion and allergen content of pollen. Prolonged and more severe pollen seasons are leading to worsened asthma and allergies. The interaction of pollen with urban air pollutants could also lead to an increased effect of aeroallergens on allergic patients, with a greater likelihood of the development of an allergic respiratory disease in sensitized subjects and exacerbation of symptomatic patients. Air pollution could induce damage to airways mucosa, thus promoting sensitization of the airways; also it could increase the expression of allergenic proteins (allergen contents of pollen produce by plants is increased by higher temperature and $\mathrm{CO}_{2}$ enriched atmosphere). By increasing pollen concentration or making the airways susceptible to allergens, the climate change and air pollution have a negative impact on human health.
\end{abstract}

Keywords: air pollutants, allergic diseases, asthma, climate change, pollen

Climate change is unequivocal and represents a possible threat for patients affected by allergic conditions (Cecchi et al., 2010). Climate change, if present, is associated with atmospheric warming, so-called "global warming", as well as volatile weather patterns, leading to more severe winters at a given latitude (since cold air typically further north in latitude is pushed south) and hotter summer months, when the earth is closer to the sun (Petoukhov et al., 2010). Global average temperature has increased by more than $0.7^{\circ} \mathrm{C}$ over the past 100 years. The Intergovernmental Panel on Climate Change (IPCC) projects that the average global surface air temperatures in the years 2090-2099 are likely to be between 1.8 and $4.0^{\circ} \mathrm{C}$ warmer than those in 1980-1999, depending on which climate scenarios are input into the models. Europe for example has experienced a progressive warming $+0.9^{\circ} \mathrm{C}$ for 1901 2005 (IPCC Climate change, 2007). In addition to global warming, some regions, including northern Europe, are projected to experience increased rainfall while others, including the Mediterranean, are expected to experience substantial droughts. Extreme weather events, such as heat waves, heavy precipitation and thunderstorms, are also predicted to increase over the next few decades (Cecchi et al., 2010).
Because of the climate changes the temporal distribution and concentration of ambient pollen could be increased. The mechanism which is leading to these consequences could be: a) because of higher temperature we could face a longer pollen seasons (it seems that if the pollen concentrations remain at high value for several consecutive days then people predisposed to allergic diseases and patients with asthma could develop a full allergic response) (Darrow et al., 2012); b) wet conditions and especially thunderstorms (which are increasing because of climate change) will produce a rupture of pollen grains and release smaller part of their content, these smaller parts are respirable particles $(0.5-2 \mu \mathrm{m})$ and could go to lower airways and trigger an asthma attack (grass pollens, particularly, after rupture by osmotic shock will release a high quantity of paucimicronic allergenic particles) (D’Amato, 2011; D'Amato et al., 2013); c) wind speed (could trigger production and dissemination) and transition of cold fronts (cold air induce bronchoconstriction in asthmatic patients); because of environmental changes, land use and long transportation allergenic pollens could arrive in new areas and will induce new sensitizations in people with atopic predisposition who did not have prior allergies to that type of pollen (Cecchi et al., 2010). 
Since 1985 , a new association between a thunderstorm and an asthma outbreak was found, the term of "Thunderstorm-associated asthma" is being used since then to describe that specific type of asthma. The authors observed that under wet conditions or during thunderstorms pollen grains may, after rupture by osmotic shock, release part of their content, including respirable, allergen-carrying starch granules $(0.5-2.5 \mu \mathrm{m})$ into the atmosphere. Because of their very small size, these starch granules can penetrate the lower airways and induce the appearance of bronchial allergic symptoms (Packe et al., 1985; D’Amato, 2011).

Since the first report of this phenomenon in the United Kingdom in 1985, further episodes characterized by an increased number in emergency room visits and hospital admissions by asthma in association with thunderstorms have been reported in several parts of the world (Cecchi et al., 2010). According to current climate change scenarios, there will be an increase in intensity and frequency of heavy rainfall episodes, including thunderstorms, over the next few decades, which can be expected to be associated with an increase in the number and severity of asthma attacks both in adults and in children (Solomon et al., 2007).

In other words, the occurrence of these epidemics is closely linked to thunderstorms and they are limited to late spring and summer when there are high levels of airborne pollen grains. There is a close temporal association between the arrival of the thunderstorm, a major rise in the concentration of pollen grains and the onset of epidemics. As a consequence, subjects affected by pollen allergy should be alert to the danger of being outdoors during a thunderstorm in the pollen season (D'Amato et al., 2013).

The changes in distribution and concentration of ambient pollen will increase the morbidity of asthma and allergic diseases, also the visits to emergency rooms (Darrow et al., 2012).

Asthma is a non-communicable disease and together with allergic diseases are now major public health problems, because their prevalence has increased dramatically over the past few decades (World Health Organization, NCD Country Profiles, 2011).

Ambient pollen independently contributes to asthma morbidity (Darrow et al., 2012). Pollen allergenicity is linked to allergen concentrations and is a major determinant of the health effects in sensitized patients (Cecchi et al., 2010).

There are several studies which sustain the theories regarding the effect of climate change on respiratory health. In Poznan, in western Poland between 1995 and 2004 there were studied the Artemisia species pollen (Stach et al., 2007). Temperature was directly correlated with daily Artemisia species pollen levels; relative humidity was inversely correlated. Twelve percent of patients had a positive skin-prick test reaction to Artemisia species. Their symptoms were rhinitis and conjunctivitis (15\%), atopic dermatitis $(15 \%)$, chronic urticaria (14.3\%), bronchial asthma (2.4\%), and facial and disseminated dermatitis (1.3\%). Elevated specific IgE concentrations were detected in the sera of $10.1 \%$ of patients. Pollen season intensity was also found to be highly influenced by rainfall in the previous weeks. Trends toward earlier season starts and longer duration, possibly caused by climate change, may have had an impact on this allergic Polish population (Stach et al., 2007).

In Northern Europe trends in airborne birch pollen levels studied over 20 to 33 years indicated start date for pollen release was significantly earlier in cities from Denmark, England, Belgium, Switzerland, Austria, and the Netherlands (Fitter et al., 2002; Kelly et al., 2008). In addition, significant increases in the cumulative season birch pollen totals were registered from locations in Denmark, England, Switzerland, and the Netherlands. Other European species, including Alnus, Corylus, Quercus, Fagus, Platanus, Urtica, Ulmus, Juniperus, and Salix, reported either earlier seasons, increased cumulative seasonal totals or both (Barnes et al., 2013). In North America sampling reported significant increases in cumulative seasonal totals of Juniperus, Quercus, Carya, and Betula pollen from 1987 through 2000 (Levetin et al., 2008).

Respiratory allergy induced by antigens released by pollen grains is very common (D'Amato et al., 2001). For instance, between $8 \%$ and $35 \%$ of young adults in countries of the European Community have IgE serum antibodies to grass pollen allergens (Burney et al., 1997). The cost of pollen allergy in terms of impaired work fitness, sick leave, physician visits and drug prescriptions is very high. Also it was proved that subjects living in urban areas tend to be more affected by plant-derived respiratory disorders than those living in rural areas (Riedler et al., 2000; Braun-Fahrländer et al., 1999).

Urban areas are responsible for the increase in anthropogenic greenhouse gas concentration. It was showed that exposure to air pollution will increase the response of the airways to inhaled allergens in susceptible patients (D’Amato, 2011).

Air pollution is associated with many signs of asthma exacerbation, such as increased bronchial hyperresponsiveness, increased medication use, and increased visits to emergency departments and hospital admissions. Outdoor air pollution concentrations result from intense energy consumption and exhaust emissions from automobiles. Urban air pollution is a serious public health hazard. Laboratory studies have confirmed epidemiologic evidence that air pollution adversely affects lung function in patients with asthma.

Through which mechanism air pollution could induce air sensitization and increase prevalence of allergic and asthma disease? There are different theories.

Air pollution could induce damage to airways mucosa and impaired mucociliary clearance and so may facilitate the access of inhales allergens to the cells of the immune system through an easier penetration (D'Amato, 2011), 
648

thus promoting sensitization of the airway. Consequently, a more severe allergic antibody (immunoglobulin IgE-mediated) response to aeroallergens and airway inflammation could account for increased prevalence of allergic respiratory diseases in polluted urban areas (Szema, 2011).

Due to the environmental threats (in particularly air pollution) plants could increase the expression of allergenic proteins (Cecchi et al., 2010). It seems that the pollen grains collected from roadsides with heavy traffic or from areas where air pollution is very high are covered with a large amount of small particles ( $<5 \mu \mathrm{m}$ in diameter). The road traffic was and will remain for several years the main contributor to air pollution (D’Amato, 2011).

Particulate matter (PM) is the most serious air pollution problem and it appears to be the component of air pollution most consistently associated with adverse health effects. PM is a mixture of solid and liquid particles of different origin, size and composition among which pollen grains and other vegetable particles carrying allergens and mold spores (D'Amato, 2011). Inhalable PM that can reach the lower airways is measured as PM10 (less than $10 \mu \mathrm{m}$ in aerodynamic diameter) and PM2.5 (less than $2.5 \mu \mathrm{ms}$ ). Human lung parenchyma retains PM2.5, while particles larger than $5 \mu \mathrm{m}$ and $<10 \mu \mathrm{m}$ only reach the proximal airways where they are eliminated by mucociliary clearance if the airway mucosa is intact (D’Amato G, 2011).

In many geographical areas particulate air pollution is significantly associated with enhanced mortality from respiratory and cardiovascular diseases, exacerbation of allergic asthma, chronic bronchitis, respiratory tract infection and hospital admissions (Brunekreef et al., 2000). In 1994, The World Health Organization estimated that inhalation of particulate matter is responsible for 500,000 excess deaths each year worldwide (United Nations Environment Program, 1994).

Another cause that can explain why people living in urban areas tend to be more affected by allergic respiratory diseases, than those living in rural areas, is the increased production of $\mathrm{CO}_{2}$ with climate changes.

Plant biology is directly affected by rising $\mathrm{CO}_{2}, \mathrm{CO}_{2}$ being the sole supplier of carbon for photosynthesis. As the concentration of atmospheric $\mathrm{CO}_{2}$ has increased by $22 \%$ in the last 50 years, and all climate change scenarios project a further increase by 2100 (IPCC, 2007), and given the other projected changes in climate, a number of effects on plants involved in human health can be anticipated in the future (Ziska et al., 2009).

Pollen allergenicity is linked to allergen concentrations and is a major determinant of the health effects in sensitized patients. Some studies report an increase in the allergen content of pollen produced by plants growing at higher temperature and in $\mathrm{CO}_{2}$-enriched atmosphere (Singer et al., 2005). Concentrations of the ragweed (Ambrosia artemisiifolia) major allergen (Amb a 1) increases in a $\mathrm{CO}_{2}$-enriched atmosphere, concentrations being selected according to future climate change scenarios. This suggests that increased $\mathrm{CO}_{2}$ could potentiate the sensitization rate and/or severity of symptoms in ragweed allergy (Cecchi et al., 2010).

Also, the fertilizing effects of increased carbon dioxide on plants have been extensively studied in greenhouse, growth chamber, and whole ecosystem field experiments (Rogers et al., 2006). Ragweed flowers earlier and produces more pollen in urban locations where carbon dioxide concentrations and temperatures are higher. Experiments indicate that when carbon dioxide levels double, individual ragweed plant pollen production increases 30\% to $90 \%$ (Rogers et al., 2006; Barnes et al., 2012).

In summary, although this increase may be beneficial for food plant production, the practicing allergist can expect to see patients affected from the effect of increasing amounts of pollen and longer pollen seasons over the coming decades (Barnes et al., 2012).

In Romania, the most common is allergy to grass pollen. Grass pollen (Dactylis, Poa, Lolium, Halcus, Cynodon, Festuca, Alopecururs) occurs in early May and reaches a maximum between May 25 to June 10 and July 15 to 20 . It is during this period that anemophyle (windborne) pollens increase their allergizing ability especially if the climate is dry and hot. Rains, by driving pollen with water droplets and depositing it on the ground, lower their concentration in the atmosphere. Correlated with this phenomenon, the symptoms of gramineous pollen allergies ameliorate in the rainy days and vice versa (Ursu et al., 2012).

Also, an association between the month of birth and the risk of allergic sensitization or asthma later in life has been found in numerous studies (Gazala et al., 2006; Linneberg et al., 2006). One possible explanation is that exposure to seasonal allergens in the perinatal period may contribute to the development of atopic disease. Children born after a season of extremely high birch pollen (whose mothers were exposed during pregnancy) do not have an increased risk for developing atopy (Kihlstrom et al., 2003). On the other hand, higher exposure to spores and pollens in the first 3 months of life has been associated with an increased risk of early wheezing (Harley et al., 2009). This indicates that exposure to aeroallergens before birth is less important in the development of allergy than exposure in possibly the most susceptible period during the first 3 months of life (Cecchi et al., 2010).

We have to ask ourselves if all the climate changes that occur nowadays have a negative impact on human health, meaning that prolonged and more severe pollen seasons are leading to worsened asthma and allergies.

Studying the effect of climate change on prevalence and morbidity of asthma and allergic diseases will help us to better understand the mechanisms which are responsible for these changes. Therefore we could take some measures: do not let the predispose people to go out during thunderstorm; move the people in another area when their place is with a high concentration of pollens; or changing the management of the disease through increasing the control 
treatment in the period with high concentration of allergens (Darrow et al., 2012; D'Amato et al., 2011; D'Amato et al., 2013; Cecchi et al., 2010).

Also, additional research on exposure-outcome associations (Beggs, 2010) should be done in order to facilitate a wide range of public health measures to improve primary (management of allergenic plants, pollen surveillance and warning systems, and building and ventilation strategies), secondary (patient education and medical management to reduce the development of allergic disease), and tertiary prevention (enhanced access to medical care to palliate the symptoms of allergic respiratory disease and reduce the severity of exacerbations when they occur) of aeroallergenrelated disease.

\section{References}

Barnes CS, Alexis NE, Bernstein JA, Cohn JR, Demain JG, Horner E, Levetin E, Nel A, Phipatanakul W (2013). Climate Change and Our Environment: The Effect on Respiratory and Allergic Disease. J Allergy Clin Immunol Pract $1(2): 137-141$.

Beggs PJ (2010). Adaptation to impacts of climate change on aeroallergens and allergic respiratory diseases. Int J Environ Res Public Health 7:3006-21.

Braun-Fahrländer C, Gassner M, Grize L, Neu U, Sennhauser FH, Varonier HS, Vuille JC, Wüthrich B (1999). Prevalence of hay fever and allergic sensitization in farmers' children and their peers living in the same rural community. SCARPOL team. Swiss Study on Childhood Allergy and Respiratory Symptoms with Respect to Air Pollution. Clin Exp Allergy 29:28-3.

Brunekreef B, Hoek G, Fischer P, Spieksma FT (2000). Relation between airborne pollen concentrations and daily cardiovascular and respiratory-disease mortality. Lancet 355:15171518.

Burney P, Malmberg E, Chinn S, Jarvis D, Luczynska C, Lai E (1997). The distribution of total and specific serum $\operatorname{IgE}$ in the European Community Respiratory Health Survey. J Allergy Clin Immunol 99:314-322.

Cecchi L, D’Amato G, Ayres JG, Galan C, Forastiere F, Forsberg B, Gerritsen J, Nunes C, Behrendt H, Akdis C, Dahl R, Annesi-Maesano I. (2010). Projections of the effects of climate change on allergic asthma: the contribution of aerobiology. Allergy 65:1073-1081.

Chen Y, Forsyth E, Pan K, Szema A, Szema K, Chenrachasit P (2006). Atmospheric temperature and pollen counts impact New York City asthma ER visits. J Allergy Clin Immunol 125(2 suppl 1):Ab208.

D'Amato G, Bonini S, Bosquet J, Durham SR, Platts-Mills TAE (2001). Pollenosis 2000: Global Approach. Naples, Italy JGC Editions.

D'Amato G (2011). Effects of climatic changes and urban air pollution on the rising trends of respiratory allergy and asth- ma. Multidiscip Respir Med 6(1):28-37.

D’Amato G, Baena-Cagnani CE, Cecchi L, Maesano IA, Nunes C, Ansotegui I, D’Amato M, Liccardi G, Sofia M, Canonica WG (2013). Climate change, air pollution and extreme events leading to increasing prevalence of allergic respiratory diseases. Multidiscip Respir Med 8:12.

Darrow LA, Hess J, Rogers CA, Tolbert PE, Klein M, Sarnat SE (2012). Ambient pollen concentrations and emergency department visits for asthma and wheeze. J Allergy Clin Immunol 130(3):630-638.

Fitter AH, Fitter RS (2002). Rapid changes in flowering time in British plants. Science 296:1689-1691.

Gazala E, Ron-Feldman V, Alterman M, Kama S, Novack L (2006). The association between birth season and future development of childhood asthma. Pediatr Pulmonol 41:1125-1128.

Harley KG, Macher JM, Lipsett M, Duramad P, Holland NT, Prager SS, Ferber J, Bradman A, Eskenazi B, Tager IB (2009). Fungi and pollen exposure in the first months of life and risk of early childhood wheezing. Thorax 64:353-358.

IPCC (2007). Climate change 2007: the physical science basis. In: Solomon S, Qin D, Manning M, Chen Z, Marquis M, Averyt KB, Tignor M, Miller HL (eds). Contribution of Working Group I to the Fourth Assessment Report of the Intergovernmental Panel on Climate Change. Cambridge, United Kingdom and New York, NY, USA: Cambridge University Press: 996 pp.

Kelly AE, Goulden ML (2008). Rapid shifts in plant distribution with recent climate change. Proc Natl Acad Sci 1182311826.

IPCC (Intergovernmental Panel on Climate Change) (2007). Climate Change 2007: Impacts, Adaptation and Vulnerability. Geneva IPCC Secretariat.

Kihlstrom A, Lilja G, Pershagen G, Hedlin G (2003). Exposure to high doses of birch pollen during pregnancy, and risk of sensitization and atopic disease in the child. Allergy 58:871877.

Levetin E, Van de Water P (2008). Changing pollen types/concentrations/distribution in the United States: fact or fiction? Curr Allergy Asthma Rep 8:418-24.

Linneberg A, Simonsen JB, Petersen J, Stensballe LG, Benn CS (2006). Differential effects of risk factors on infant wheeze and atopic dermatitis emphasize a different etiology. J Allergy Clin Immunol 117:184-189.

Packe GE, Ayres JG (1985). Asthma outbreak during a thunderstorm. Lancet 199-204.

Petoukhov V, Semenov VA (2010). A link between reduced Barents-Kara sea ice and cold winter extremes over northern continents. J Geo Phys Res 115:D21111.

Riedler J, Eder W, Oberfeld G, Schreuer M (2000). Austrian children living on a farm have less hay fever, asthma and allergic sensitization. Clin Exp Allergy 30:194-200.

Rogers CA, Wayne PM, Macklin EA, Muilenberg ML, Wagner 
650

CJ, Epstein PR, Bazzaz FA (2006). Interaction of the onset of spring and elevated atmospheric $\mathrm{CO}_{2}$ on ragweed ( $\mathrm{Am}$ brosia artemisiifolia L.) pollen production. Environ Health Perspect 114:865-869.

Singer BD, Ziska LH, Frenz DA, Gebhard DE, Straka JG (2005). Increasing Amb a 1 content in common ragweed (Ambrosia artemisiffolia) pollen as a function of rising atmospheric $\mathrm{CO}_{2}$ concentration. Funct Plant Biol 32:667-670.

Solomon S, Qin D, Manning M, Alley RB, Berntsen T, Bindoff NL et al (2007). Technical Summary. In: Solomon S, Qin D, ManningM, Chen Z, Marquis M, Averyt KB, Tignor M, Miller HL, editors. Climate Change 2007: The Physical Science Basis. Contribution of Working Group I to the Fourth Assessment Report of the Intergovernmental Panel on Climate Change. Cambridge, United Kingdom and New York, NY, USA Cambridge University Press 51-54.

Stach A, García-Mozo H, Prieto-Baena JC, Czarnecka-Operacz M, Jenerowicz D, Silny W, Galán C (2007). Prevalence of Artemisia Species Pollinosis in Western Poland: Impact of Climate Change on Aerobiological Trends, 1995-2004. J Investig Allergol Clin Immunol 17(1):39-47.
Szema AM (2011). Climate change, Allergies and Asthma. JOEM 53(12):1353-1354.

United Nations Environment Program and WHO Report (1994). Air pollution in the world's megacities. A report from the U.N. Environment Programme and WHO. Environment 36:5-37.

Ursu C, Ioan CC, Veres L (2012). Management of respiratories allergies in the context of sustainable development programs. Alergologia http://www.sraic.eu/inpage/alergologia-1-2012/ (abstract).

World Health Organization - NCD Country Profiles (2011).

Ziska LH, Epstein PR, Schlesinger WH (2009). Rising $\mathrm{CO}_{2}$, climate change, and public health: exploring the links to plant biology. Environ Health Perspect 117:155-158. 